\title{
PEMETAAN KOSENTRASI LIMBAH MINYAK PADA AIR TANAH DI DAERAH KELURAHAN TALANG MANDI KECAMATAN MANDAU KABUPATEN BENGKALIS PROVINSI RIAU
}

\author{
Hilda Yetri ${ }^{1}$, Helfia Edial ${ }^{2}$, Triyatno ${ }^{2}$ \\ Program Studi Pendidikan Geografi, \\ Fakultas Ilmu Sosial, Universitas Negeri Padang \\ email: hyetry@ rocketmail.com
}

\begin{abstract}
Abstrak
Tujuan penelitian ini adalah (1) mengetahui persebaran limbah minyak di daerah sekitar tambang minyak bumi pada daerah Kelurahan Talang Mandi. (2) Mengetahui kadar pencemaran yang terdapat pada air tanah yang telah tercemar limbah minyak pada daerah Kelurahan Talang Mandi. Hasil penelitian menunjukkan bahwa: (1) Limbah yang dihasilkan oleh pertambangan mencemari air tanah atau air. (2) Dari 9 sampel yang dianalisis, sumur 1 mempunyai kadar belerang paling tinggi dengan jumlah 0,009 $\mathrm{mg} / \mathrm{L}$, sementara sumur 8 dan 9 memiliki kadar belerang yang paling rendah dengan jumlah yang sama yaitu $0,001 \mathrm{mg} / \mathrm{L}$. (3) berdasarkan 9 sampel yang dianalisis, sumur 1 mempunyai kadar amoniak paling tinggi dengan jumlah $0,472 \mathrm{mg} / \mathrm{L}$, sementara sumur 9 memiliki kadar amoniak yang paling rendah dengan jumlah $0,153 \mathrm{mg} / \mathrm{L}$. (4) kadar DO paling tinggi terdapat pada sumur 9 dengan jumlah $7,01 \mathrm{mg} / \mathrm{L}$, sementara sumur 1 memiliki kadar DO yang paling rendah dengan jumlah $5,86 \mathrm{mg} / \mathrm{L}$. Semakin tinggi kandungan DO di dalam air maka semakin bagus kualitas airnya. (5) sumur 1 mempunyai kadar nikel paling tinggi dengan jumlah $0,083 \mathrm{mg} / \mathrm{L}$, sementara sumur 3 memiliki kadar nikel yang paling rendah dengan jumlah $0,043 \mathrm{mg} / \mathrm{L}$. (6) sumur 1 mempunyai kadar natrium paling tinggi dengan jumlah $258,33 \mathrm{mg} / \mathrm{L}$, sementara sumur 5 memiliki kadar natrium yang paling rendah dengan jumlah $177,28 \mathrm{mg} / \mathrm{L}$, Dan hasil ini kemudian di petakan.
\end{abstract}

Kata Kunci : Limbah minyak, Pencemaran air Tanah

\begin{abstract}
This research was purpose (1) to find out the spread of waste oil around petroleum mining in Talang Mandi urban village. (2) to find out pollution levels on groundwater which has been contaminated by waste oil in Talang Mandi, Mandau village. Research shows that : (1) waste generated by the mining contaminate ground water or water. (2) from 9 samples, wells 1 has the highest sulfur content that is numbered 0,009 $\mathrm{mg} / \mathrm{L}$, while, wells 8 and 9 the lowest in same number $0,001 \mathrm{mg} / \mathrm{L}$, (3) based on 9 samples, wells 1 has the highest ammonia content that is numbered 0,472 $\mathrm{mg} / \mathrm{L}$, while wells 9 has the lowest that is numbered $0,153 \mathrm{mg} / \mathrm{L}$. (4) the highest DO levels found in wells 9 that is numbered 7,01 $\mathrm{mg} / \mathrm{L}$, while the lowest DO levels found in wells 1 that is numbered 5,86 $\mathrm{mg} / \mathrm{L}$. The higher DO levels in the water it will make it better. (5) wells 1 has the highest nickel content with $0,083 \mathrm{mg} / \mathrm{L}$, while wells has the lowest with $0,043 \mathrm{mg} / \mathrm{L}$. (6) wells 1 has the highest natrium content with $258,33 \mathrm{mg} / \mathrm{L}$, while wells 5 has the lowest with $177,28 \mathrm{mg} / \mathrm{L}$. Then the result is mapped.
\end{abstract}

Keyword: Waste Oil, Groundwater Contamination

\footnotetext{
${ }^{1}$ Mahasiswa Program Studi Pendidikan Geografi untuk Wisuda September 2017

${ }^{2}$ Dosen Jurusan Geografi Fakultas Ilmu Sosial Universitas Negeri Padang
} 


\section{PENDAHULUAN}

Munculnya industri-industri pertambangan di Indonesia berdampak positif dan negatif bagi masyarakat dan negara. Dampak positif adanya industri pertambangan antara lain menciptakan lapangan pekerjaan bagi masyarakat, hasil produksi tambang dapat digunakan untuk memenuhi permintaan pasar domestik maupun pasar internasional, sehingga hasil ekspor tambang tersebut dapat meningkatkan pendapatan dan pertumbuhan ekonomi negara. Industri pertambangan juga dapat menarik investasi asing untuk menanamkan modalnya di Indonesia. Kemudian, di sisi lain, industri pertambangan juga mempunyai dampak

Pencemaran lingkungan oleh
minyak sangat berbahaya bagi
kesehatan manusia. Air yang sudah tercemar oleh limbah minyak bumi, tidak bisa digunakan oleh manusia lagi. Selain merusak kesehatan manusia, juga dapat merusak habitat makhluk hidup di dalam air, seperti ikan-ikan akan keracunan dan mati.

Daerah Riau, Kabupaten

Bengkalis-Kecamatan Mandau limbah yang dihasilkan oleh sektor minyak bumi lebih besar. Selain daerah ini merupakan pemukiman penduduk, disini juga terdapat lokasi pertambang-an minyak bumi. masalah ini telah di atasi sebelumnya, penduduk yang bertempat tinggal di daerah lokasi pertambangan dipindahkan dan diganti rugi oleh perusahaan. namun, tidak semua penduduk yang mau pindah dikarenakan biaya ganti rugi tanah mereka tidak sepadan dengan yang diberikan oleh perusahaan tersebut. Daerah lokasi pertambangan diberi pagar pembatas dengan pemukiman penduduk, dan juga dibuat jalan pembatas menuju lokasi.
Meskipun begitu, limbah yang dihasilkan oleh pertambangan masih mencemari air tanah atau air sumur penduduk, dan ini menimbulkan protes dari penduduk setempat kepada perusahaan yang bersangkutan. Aksi protes ini dimuat oleh media masa seperti detik news dan berbagai media lainnya yang gunanya agar perusahaan mau mengganti rugi. Proyek tersebut dimulai pada tahun 2009 di Kelurahan Talang Mandi, dan air sumur warga mulai berubah jadi bercampur minyak dan limbah setahun kemudian pada 2010. Daerah ini berdekatan dengan tempat pembuangan limbah, dan pencemaran ini terlihat lebih pekat pada saat musim kemarau. Dampak pencemaran itu membuat warga kesulitan mendapatkan air bersih, selain itu timbul penyakit gatal-gatal pada kulit. Akibatnya, warga harus mengeluarkan biaya lebih untuk membeli air mineral untuk minum dan terpaksa menunggu hujan guna mendapatkan air. Sebagian warga yang kurang mampu memilih tinggal sementara di rumah kerabatnya.

Persebaran limbah sampai kepemukiman warga dan mencemari air tanah (sumur) mereka yang berada di sekitar daerah tambang, sehingga air sumur tidak dapat digunakan lagi untuk kebutuhan sehari-hari, dan hingga kini belum diketahui sampai dimana limbah tersebut tersebar di daerah kelurahan Talang Mandi. Berdasarkan rentetan permasalahan yang telah di ungkapkan maka dilakukanlah penelitian dengan judul “ Pemetaan Konsentrasi Limbah Minyak pada Air Tanah di daerah Kelurahan Talang Mandi Kecamatan Mandau Kabupaten Bengkalis Provinsi Riau". 


\section{METODE PENELITIAN}

Penelitian ini tergolong pada penelitian deskriptif analisis. Deskriptif analisis ialah metode yang bertujuan mendeskripsikan atau memberi gambaran terhadap suatu objek penelitian yang diteliti melalui sampel atau data yang telah terkumpul. Metode ini menggunakan data sekunder yang terdiri dari data peta. Data peta di peroleh dari Bappeda Kecamatan Mandau. Untuk memastikan keakuratan data di lakukan observasi lapang dengan menentukan beberapa titik sampel. Penelitian ini bertujuan untuk mendeskripsikan apa yang sedang berlaku pada saat ini, di dalamnya terdapat upaya untuk mendeskripsikan, mencatat, menganalisis, dan menginterpretasikan kondisi-kondisi yang terdapat pada saat ini. Sedangkan data primer didapatkan dari wawancara langsung kepada mesyarakat setempat.

Penelitian ini akan dilaksanakan di daerah Kecamatan Mandau Kabupaten Bengkalis Provinsi Riau.

Berdasarkan sumber data, maka data yang akan digunakan pada penelitian ini adalah data primer dan sekunder. Data primer diperoleh dari pengukuran langsung di lapangan yang terdiri dari suhu, rasa, bau, warna, dan ditambah lagi uji laboratorium sedangkan data sekundernya berupa peta Kecamatan dan peta lokasi penelitian.

Penentuan wilayah penelitian ini berdasarkan teknik Purposive Sampling. Teknik purpose sampling adalah teknik mengambil sampel yang dilakukan secara sengaja dan telah sesuai dengan semua persyaratan sampel yang akan diperlukan.

Teknik purposive sampling pada dasarnya dilakukan sebagai sebuah teknik yang secara sengaja mengambil sampel tertentu yang telah sesuai dan memenuhi segala persyaratan yang dibutuhkan, meliputi : sifat - sifat, karakteristik, ciri, dan kriteria sampel tertentu, yang dalam hal ini pengambilan sampel juga harus mencerminkan populasi dari sampel itu sendiri. Sebuah sampel yang tidak memenuhi kriteria yang telah ditentukan, akan berdampak tidak baik pada hasil penelitian yang akan dilakukan karena di dalam sebuah penelitian akan selalu dibutuhkan sebuah / sesuatu yang merupakan cerminan utuh dari sebuah populasi yang akan diteliti. Pengambilan sampel dengan cara, mengambil sampel air tanah pada setiap radius yang telah di tentukan yaitu 150 meter dan kelipatannya dimulai dari dengan patokan lokasi penelitian (daerah tambang) , untuk masing-masing radius diambil satu titik sebelah timur, satu titik sebelah utara, dan satu titik selatan, begitu seterusnya sampai jarak $450 \mathrm{~m}$, hingga nantinya diperoleh sembilan sampel yang akan diuji labor dan diteliti lebih lanjut.

Analisis yang digunakan untuk mengetahui konsentrasi limbah minyak bumi terhadap air tanah di daerah Kelurahan Talang Mandi dilakukan dengan cara :

a. Survey daerah tercemar. Mengambil sembilan titik dengan menggunakan GPS setiap jarak $150 \mathrm{~m}$ dari lokasi tambang. Lalu diambil sampel airnya.

b. Setelah sembilan sampel diproleh dari sembilan titik yang telah ditentukan, sampel - sampel tersebut diuji labor, di laboratorium Unit Pelaksana Teknis Pengujian Material, Pekanbaru dengan parameter penentu yaitu ; belerang (H2S), amoniak (NH3), oksigen terlarut / $\mathrm{DO}$, nikel $(\mathrm{Ni})$, dan natrium $(\mathrm{Na})$. 
c. hasil uji labor tersebut di olah. Dengan membuat tabel perparameternya, yang bertujuan untuk mengetahui daerah mana yang paling tercemar dan mengetahui tingkat pencemarannya (rendah, sedang, dan tinggi)

d. Pembuatan peta wilayah tercemar. Dengan peta dasar geologi, model peta menggunakan softwere arc gis 9. Versi 9.3. dibuat grafik daerah yang paling terkonsentrasi limbah minyak bumi.

\section{HASIL PENELITIAN \\ DANPEMBAHASAN \\ Hasil Penelitian}

Penelitian yang dilakukan terdiri dari Persebaran limbah minyak di Kelurahan Talang Mandi dan kadar pencemaran yang terdapat pada air tanah yang telah tercemar limbah minyak pada daerah Kelurahan Talang Mandi. Penelitian ini dilakukan selama sebulan pada musim kemarau yang terdapat hujan yang sedikit. untuk lebih jelas dapat diuraikan sebagai berikut:

1. Persebaran limbah minyak pada daerah Wonosobo, Kelurahan Talang Mandi

Kehadiran limbah berdampak negatif tehadap lingkungan terutama bagi kesehatan manusia., sehingga perlu dilakukan penanganan terhadap limbah Berdasarkan hasil penelitian, tentang persebaran limbah minyak pada air sumur di sembilan (9) titik daerah penelitian didapatkan data sebagai berikut:

Tabel 5

Sebaran Titik Sampel

\begin{tabular}{|r|l|c|c|}
\hline No. & $\begin{array}{l}\text { Titik } \\
\text { Sampel }\end{array}$ & $\begin{array}{c}\text { Jarak dari } \\
\text { sumur bor }\end{array}$ & Arah \\
\hline 1 & Sumur I & $\begin{array}{c}150 \mathrm{~m} \text { dari } \\
\text { titik bor }\end{array}$ & Timur \\
\hline 2 & Sumur II & $\begin{array}{c}150 \mathrm{~m} \text { dari } \\
\text { titik bor }\end{array}$ & Utara \\
\hline 3 & Sumur & $150 \mathrm{~m}$ dari & Selatan \\
\hline
\end{tabular}

\begin{tabular}{|c|c|c|c|}
\hline & III & titik bor & \\
\hline 4 & $\begin{array}{l}\text { Sumur } \\
\text { IV }\end{array}$ & $\begin{array}{l}300 \mathrm{~m} \text { dari } \\
\text { titik bor }\end{array}$ & Timur \\
\hline 5 & $\begin{array}{l}\text { Sumur } \\
\text { V }\end{array}$ & $\begin{array}{l}300 \mathrm{~m} \text { dari } \\
\text { titik bor }\end{array}$ & Utara \\
\hline 6 & $\begin{array}{l}\text { Sumur } \\
\text { VI }\end{array}$ & $\begin{array}{l}300 \mathrm{~m} \text { dari } \\
\text { titik bor }\end{array}$ & Selatan \\
\hline 7 & $\begin{array}{l}\text { Sumur } \\
\text { VII }\end{array}$ & $\begin{array}{l}450 \mathrm{~m} \text { dari } \\
\text { titik bor }\end{array}$ & Timur \\
\hline 8 & $\begin{array}{l}\text { Sumur } \\
\text { VIII }\end{array}$ & $\begin{array}{l}450 \mathrm{~m} \text { dari } \\
\text { titik bor }\end{array}$ & Utara \\
\hline 9 & $\begin{array}{l}\text { Sumur } \\
\text { IX }\end{array}$ & $\begin{array}{l}450 \mathrm{~m} \text { dari } \\
\text { titik bor }\end{array}$ & Selatan \\
\hline
\end{tabular}

Sumber : pengolahan data primer 2016

2. Kadar pencemaran yangterdapat pada air tanah yang telah tercemar limbah minyak pada daerah Wonosobo, Kelurahan Talang Mandi

a. Kadar Belerang $\left(\mathrm{H}_{2} \mathrm{~S}\right)$

Kadar $\mathrm{H}_{2} \mathrm{~S}$ yang terdapat pada air tanah di daerah Kelurahan Talang Mandi yang diperoleh dari sembilan sampel. Masing-masing sampel mempunyai kandungan $\mathrm{H}_{2} \mathrm{~S}$ yang beragam. Dari 9 sampel yang dianalisis, sumur 1 mempunyai kadar $\mathrm{H}_{2} \mathrm{~S}$ paling tinggi, sementara sumur 8 dan 9 memiliki kadar $\mathrm{H}_{2} \mathrm{~S}$ yang paling rendah. Dan sumur 2, 3, 4, 5 juga termasuk katagori kadar $\mathrm{H}_{2} \mathrm{~S}$ yang tinggi, sedangkan sumur 6 dan 7 termasuk dalam katagori normal. Dalam bentuk peta, pesebaran $\mathrm{H}_{2} \mathrm{~S}$ dapat dilihat sebagai berikut.

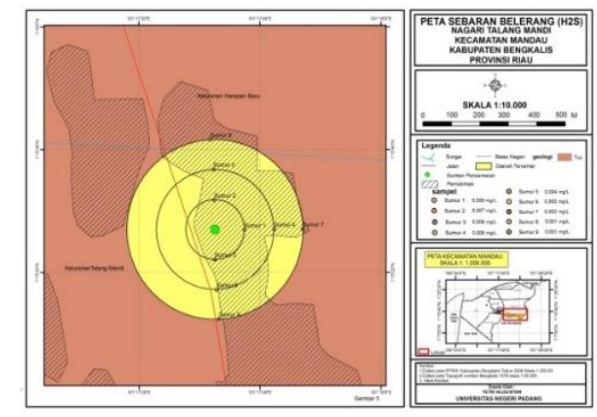

Gambar 1. Peta Sebaran H2S

b. Kadar Amoniak/Ammonia $\left(\mathrm{NH}_{3}\right)$ 
Kadar amoniak yang terdapat pada air tanah di daerah Kelurahan Talang Mandi yang diperoleh dari sembilan sampel yang telah diuji labor. berdasarkan 9 sampel yang dianalisis, sumur 1 mempunyai kadar NH-3 paling tinggi, sementara sumur 9 memiliki kadar NH-3 yang paling rendah. Sumur2, 3,4,5,6, dan 7 juga termasuk katagori kadar NH-3 yang tinggi, dan sumur 8 dan 9 termasuk normal.

Dalam bentuk peta, pesebaran amoniak dapat dilihat sebagai berikut.

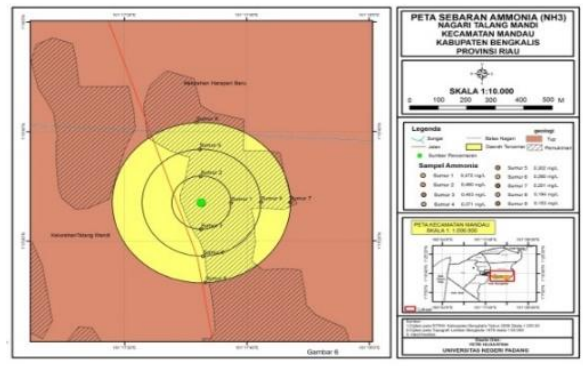

Gambar 2. Peta Sebaran NH3

c. Kadar Oksigen Terlarut (DO)

Kadar oksigen yang terdapat pada air tanah di daerah Kelurahan Talang Mandi yang diperoleh dari sembilan sampel yang telahdiuji labor. Dari 9 sampel yang dianalisis, sumur 9 mempunyai kadar DO paling tinggi, sementara sumur 1 memiliki kadar DO yang paling rendah. Dan sumur 2,3,4,5,6,7, dan 8 juga termasuk katagori kadar DO yang tinggi. Dalam bentuk peta, pesebaran DO dapat dilihat sebagai berikut.

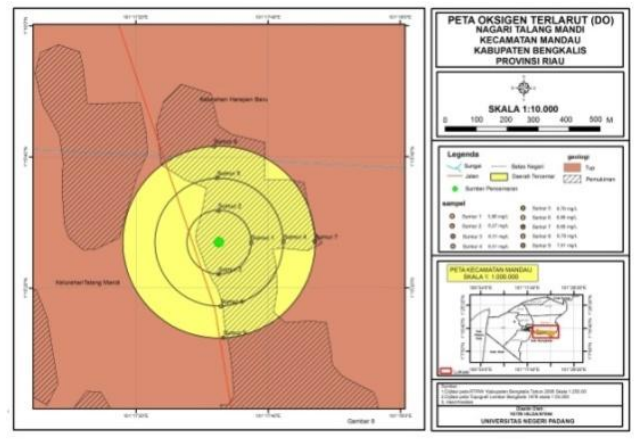

Gambar 3. Peta Sebaran DO

\section{d. Nikel (Ni)}

Kadar nikel yang terdapat pada air tanah di daerah Kelurahan Talang Mandi yang diperoleh dari sembilan sampel yang telah diuji labor. Masingmasing sampel mempunyai kandungan nikel yang beragam seperti yang terdapat pada tabel di atas. Dari 9 sampel yang dianalisis, sumur 1 mempunyai kadar nikel paling tinggi, sementara sumur 3 memiliki kadar nikel yang paling rendah. Dan sumur 2 dan 4 juga termasuk katagori kadar nikel yang tinggi, sedangkan sumur 5,6,7,8, dan 9 termasuk dalam katagori normal. Dalam bentuk peta, nikel dapat dilihat sebagai berikut.

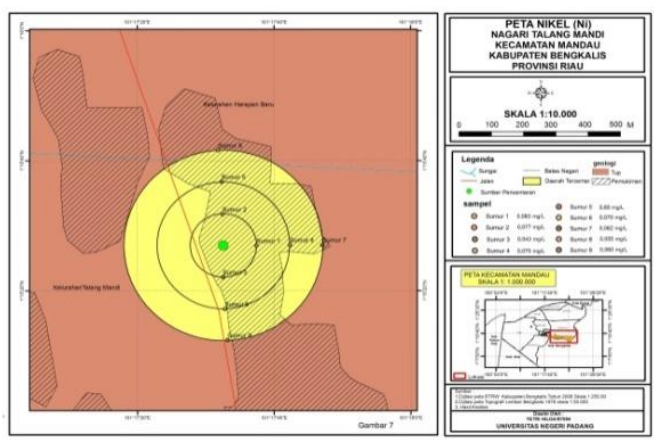

Gambar 4. Peta Sebaran Ni

e. Kadar Natrium (Na)

Kadar natrium yang terdapat pada air tanah di daerah Kelurahan Talang Mandi yang diperoleh dari sembilan sampel yang telah diuji labor. Masing-masing sampel mempunyai kandungan natrium yang beragam seperti yang terdapat pada tabel di atas. Dari 9 sampel yang dianalisis, sumur 1 mempunyai kadar natrium paling tinggi, sementara sumur 5 memiliki kadar natrium yang paling rendah. Dan sumur 3, 4, 6, dan 7 juga termasuk katagori kadar natrium yang tinggi, sedangkan sumur 2, 8, dan 9 termasuk dalam katagori normal. Dalam bentuk peta, pesebaran natrium dapat dilihat sebagai berikut. 


\section{PEMBAHASAN}

Limbah adalah buangan yang dihasilkan dari suatu proses produksi baik industri maupun domestik (rumah tangga). Limbah yang dihasilkan oleh pertambangan masih mencemari air tanah atau air sumur penduduk, air sumur warga mulai berubah jadi bercampur minyak dan limbah terlihat lebih pekat pada saat musim kemarau air tersebut terdeteksi tercampur amoniak, nitrit, total fosfat, dan besi yang diatas ambang normal.

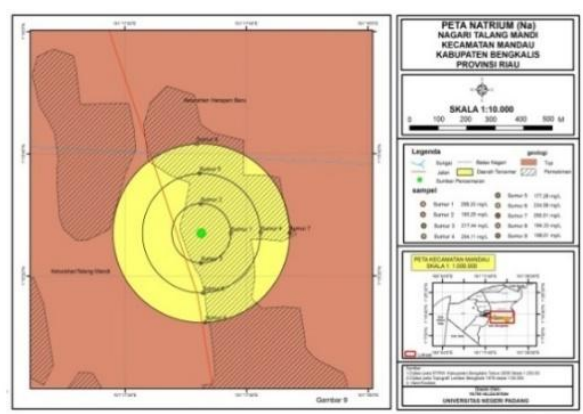

Gambar 5. Peta Sebaran Na

Kehadiran limbah dapat berdampak negatif tehadap lingkungan terutama bagi kesehatan manusia., sehingga perlu dilakukan penanganan terhadap limbah.

Limbah minyak bersifat mudah meledak, mudah terbakar, bersifat reaktif, beracun, menyebabkan infeksi dan bersifat korosif. Limbah minyak merupakan bahan berbahaya dan beracun (B3), karena sifatnya, konsentrasi maupun jumlahnya dapat mencemarkan dan membahayakan lingkungan hidup serta kelangsungan hidup manusia dan mahluk hidup lainnya. limbah cair minyak bumi terdiri dari unsur-unsur dan bahan kimia yang sangat berbahaya seperti $\mathrm{H} 2 \mathrm{~S}$ mengandung $0.73 \mathrm{ppm}$, NH3 2,0 ppm, phenol 0,76 ppm, dan logam berat.

a. Kadar Hidrogen Belerang $\left(\mathrm{H}_{2} \mathrm{~S}\right)$

Jumlah kadar $\mathrm{H}_{2} \mathrm{~S}$ yang

diperbolehkan terdapat dalam air tanah adalah 0,002 $\mathrm{mg} / \mathrm{L}$ dari 9 sampel yang di analisis, sampel sumur 1 mempunyai kadar $\mathrm{H}_{2} \mathrm{~S}$ paling tinggi yaitu $0,009 \mathrm{mg} / \mathrm{L}$, sementara sumur 8 dan 9 memiliki kadar $\mathrm{H}_{2} \mathrm{~S}$ yang paling rendah yaitu $0,001 \mathrm{mg} / \mathrm{L}$ dan sumur 2 $(0,007 \mathrm{mg} / \mathrm{L})$, sumur 3 dan $4(0,006$ $\mathrm{mg} / \mathrm{L})$, lalu sumur $5(0,004 \mathrm{mg} / \mathrm{L})$ juga termasuk katagori kadar $\mathrm{H}_{2} \mathrm{~S}$ yang tinggi, sedangkan sumur 6 dan 7 $(0,002 \mathrm{mg} / \mathrm{L})$ termasuk dalam katagori normal. Kadar $\mathrm{H}_{2} \mathrm{~S}$ yang apabila melebihi ambang batas di dalam air tanah dapat mengakibatkan bau menyengat pada air (bau seperti bau kentut) yang apabila dikosumsi terus menerus (diminum) akan menyebabkan diare. dan gas $\mathrm{H}_{2} \mathrm{~S}$ dapat melumpuhkan sistem pernafasan dan bisa mengakibatkan kematian.

b. Amoniak/Ammonia $\left(\mathrm{NH}_{3}\right)$

Jumlah kadar amoniak yang diperbolehkan dalam air tanah adalah $0,2 \mathrm{mg} / \mathrm{L}$. Berdasarkan 9 sampel yang dianalisis, sumur 1 mempunyai kadar ammonia paling tinggi yaitu 0,472 $\mathrm{mg} / \mathrm{L}$, sementara sumur 9 memiliki kadar ammonia yang paling rendah yaitu $0,153 \mathrm{mg} / \mathrm{L}$. Sumur $2(0,467$ $\mathrm{mg} / \mathrm{L})$, sumur $3(0,453 \mathrm{mg} / \mathrm{L})$, sumur 4 $(0,371 \mathrm{mg} / \mathrm{L})$, sumur $5(0,302 \mathrm{mg} / \mathrm{L})$, sumur $6(0,280 \mathrm{mg} / \mathrm{L})$, dan sumur 7 $(0,201 \mathrm{mg} / \mathrm{L})$ juga termasuk katagori kadar ammonia yang tinggi, dan sumur $8 \quad(0,194 \quad \mathrm{mg} / \mathrm{L})$ termasuk normal. amoniak dapat mengganggu kelancaran pemrosesan katalitik yang jika sampai terbawa ke dalam air, berpengaruh buruk terhadap bau, kestabilan warna.

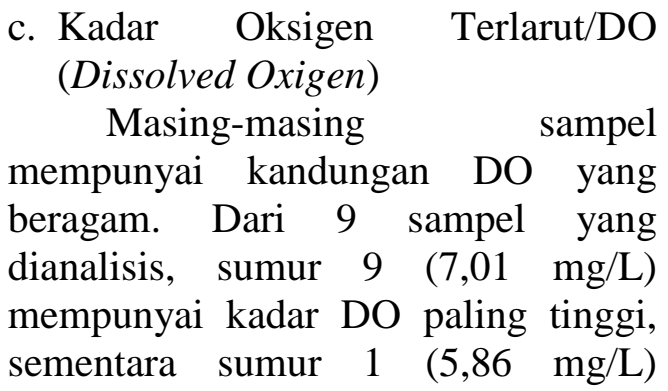


memiliki kadar DO yang paling rendah. Dan sumur $2(6,27 \mathrm{mg} / \mathrm{L})$, sumur $3(6,31 \mathrm{mg} / \mathrm{L})$, sumur $4(6,51$ $\mathrm{mg} / \mathrm{L})$, sumur $5(6,76 \mathrm{mg} / \mathrm{L})$, sumur 6 $(6,88 \mathrm{mg} / \mathrm{L})$, sumur $7(6,68 \mathrm{mg} / \mathrm{L})$, dan sumur $8 \quad(6,78 \mathrm{mg} / \mathrm{L}) \quad$ juga termasuk katagori kadar DO yang tinggi. Semakin tinggi kadar DO di dalam air, semakin bagus kualitas air nya. DO tidak menyebabkan masalah serius seperti halnya senyawa belerang dan senyawa nitrogen. Kadar oksigen terlarut yang terlalu rendah akan menimbulkan bau yang tak sedap pada air. Semakin tinggi kadar DO di dalam air, maka semakin bagus kualitas air nya. Begitu juga sebaliknya, semakin rendah DO di dalam air maka semakin buruk kualitas air nya.

\section{d. Nikel (Ni)}

Jumlah kadar nikel yang diperbolehkan di dalam air tanah adalah sejumlah $0,07 \mathrm{mg} / \mathrm{L}$. Dari 9 sampel yang dianalisis, sumur 1 $(0,083 \mathrm{mg} / \mathrm{L})$ mempunyai kadar nikel paling tinggi, sementara sumur 3 $(0,043 \mathrm{mg} / \mathrm{L})$ memiliki kadar nikel yang paling rendah. Dan sumur 2 $(0,077 \mathrm{mg} / \mathrm{L})$ dan sumur $4(0,075$ $\mathrm{mg} / \mathrm{L})$ juga termasuk katagori kadar nikel yang tinggi, sedangkan sumur 5 $(0,065 \mathrm{mg} / \mathrm{L})$, sumur $6(0,070 \mathrm{mg} / \mathrm{L})$, sumur $7(0,062 \mathrm{mg} / \mathrm{L})$, sumur $8(0,055$ $\mathrm{mg} / \mathrm{L})$, dan sumur $9(0,060 \mathrm{mg} / \mathrm{L})$ termasuk dalam katagori normal. Dalam jumlah kecil, nikel merupakan unsur penting, tetapi jika berada dalam konsentrasi terlalu tinggi akan membahayakan kesehatan manusia. kemungkinan lebih tinggi mengalami kanker paru-paru, kanker hidung, kanker laring, dan kanker prostat.

e. Kadar Natrium (Na)

Natrium yang diperbolehkan terdapat dalam air tanah adalah sejumlah $200 \mathrm{mg} / \mathrm{L}$. Dari 9 sampel yang dianalisis, sumur $1 \quad(258,33$ $\mathrm{mg} / \mathrm{L})$ mempunyai kadar natrium paling tinggi, sementara sumur 5 $(177,28 \mathrm{mg} / \mathrm{L})$ memiliki kadar natrium yang paling rendah. Dan sumur $3(217,44 \mathrm{mg} / \mathrm{L})$, sumur 4 $(204,11 \mathrm{mg} / \mathrm{L})$, sumur $6 \quad(234,58$ $\mathrm{mg} / \mathrm{L})$, dan sumur 7 (200,01 $\mathrm{mg} / \mathrm{L})$ juga termasuk katagori kadar natrium yang tinggi, sedangkan sumur 2 $(193,25 \mathrm{mg} / \mathrm{L})$, sumur $8 \quad(184,33$ $\mathrm{mg} / \mathrm{L})$, dan 9 (199,01 termasuk dalam katagori normal.

\section{PENUTUP}

\section{Kesimpulan}

Berdasarkan hasil penelitian, maka dapat disimpulkan sehubungan dengan proses pengolahan limbah, harus dibuat perkiraan terlebih dahulu dengan mengidentifikasi sumber pencemaran, fungsi dan jenis bahan, sistem pengolahan kualitas dan jenis buangan dapat disimpulkan sebagai berikut.

1. Persebaran limbah minyak pada daerah Kelurahan Talang Mandi

Limbah yang dihasilkan oleh pertambangan masih mencemari air tanah atau air sumur penduduk berubah jadi bercampur minyak dan limbah terlihat lebih pekat pada saat musim kemarau. Untuk mendeteksi hal tersebut dilakukan uji labor dengan parameter beberapa senyawa non hidrokarbon yang terkandung dalam minyak bumi diataranya belerang $\left(\mathrm{H}_{2} \mathrm{~S}\right)$, ammonia $\left(\mathrm{NH}_{3}\right)$, oksigen terlarut (DO), nikel $(\mathrm{Ni})$, dan natrium (Na).

2. Kadar pencemaran yang terdapat pada air tanah yang telah tercemar limbah minyak pada daerah Kelurahan Talang Mandi

Dari 9 sampel yang di analisis, sampel sumur 1 mempunyai kadar belerang paling tinggi yaitu 0,009 $\mathrm{mg} / \mathrm{L}$, sementara sumur 8 dan 9 (nilainya sama) memiliki kadar 
belerang yang paling rendah yaitu $0,001 \mathrm{mg} / \mathrm{L}$.

Sumur 1 mempunyai kadar amoniak paling tinggi yaitu 0,472 $\mathrm{mg} / \mathrm{L}$, sementara sumur 9 memiliki kadar amoniak yang paling rendah yaitu $0,153 \mathrm{mg} / \mathrm{L}$. amoniak dapat mengganggu kelancaran pemrosesan katalitik yang jika sampai terbawa ke dalam air, berpengaruh buruk terhadap bau, kestabilan warna.

Sumur 9 mempunyai kadar DO paling tinggi yaitu $7,01 \mathrm{mg} / \mathrm{L}$, sementara sumur 1 memiliki kadar DO yang paling rendah yaitu 5,86 mg/L. semakin tinggi DO semakin bagus kualitas airnya.

Sumur 1 mempunyai kadar nikel paling tinggi yaitu $0,083 \mathrm{mg} / \mathrm{L}$, sementara sumur 3 memiliki kadar nikel yang paling rendah yaitu 0,043 $\mathrm{mg} / \mathrm{L}$.

Sumur 1 mempunyai kadar natrium paling tinggi yaitu 258,33 $\mathrm{mg} / \mathrm{L}$, sementara sumur 5 memiliki kadar natrium yang paling rendah yaitu 177,28 mg/L.

\section{Saran}

a. Bagi masyarakat sebelum mengkonsumsi air harus mengolahnya dengan cara penyaringan, supaya air yang berwarna dan keruh dapat dijadikan untuk air minum. Kehadiran limbah dapat berdampak negatif tehadap lingkungan terutama bagi kesehatan manusia., sehingga perlu dilakukan penanganan terhadap limbah.

b. Disarankan kepada pengguna air minum (Masyarakat) agar menstabilkan sifat kimia air tanah dengan menambahkan kaporit pada air minum.

c. diharapkan pada peneliti lain agar dapat menindak lanjuti penelitian ini dimasa yang akan datang.

\section{DAFTAR PUSTAKA}

Faridiaz,S., 1992. Polusi Air dan Udara. Kanisius.;Sutrisno,T.C. dan Suciati,E.,

Fatimah,Cut. 2003. Jurnal Penyulingan, Pemrosesan, dan Penggunaan Minyak Bumi, Medan : USU press

Diana, Kadek. 2007. Pencemaran Air Tanah Akibat Pembuangan Limbah Domestik di Lingkungan Kumuh, Bali : Udayana Press

Permenkes 416_90. 28 MEI 2008

Rukaisih, Ahmad. 2004. Kimia Lingkungan, AndiOffset Yogyakarta, Jakarta.

Supeno, 2006. Kualitas air sumur dangkal berdasarkan Geologi di KecamatanRengat Barat Kabupaten Indragiri Hulu.Skripsi, Geografi FIS UNP.

Suripin, 2001. Pelestarian Sumber Daya Tanah dan Air.Semarang : Penerbit Andi.

Sastrawijaya, A, Tresna. 2009. Pencemaran Lingkungan. Jakarta:Rineka Cipta.

Indarto, $2010 . \quad$ Hidrologi. Jember:Bumi Aksara.

Wardhana, W.A., 1995. Dampak Pencemaran Lingkungan, AndiOffset Yogyakarta, Jakarta.

Permenkes RI No. 416/Menkes/Per/IX/1990, tentang, Syaratᄀ-Syarat dan Pengawasan Kualitas Air bersih; Slamet, J.S, 2007, Kesehatan Lingkungan. Gadjah Mada Pres; 